\title{
SELF-REGULATED LEARNING IN REMOTE EDUCATIONAL CONTEXT
}

\author{
Edīte Sarva, Inga Linde, Linda Daniela \\ University of Latvia, Latvia
}

\begin{abstract}
Year 2020 has introduced massive changes in the teaching and learning in traditional classroom settings all around the world as due to the abrupt outbreak of COVID-19 pandemic, schools had to introduce remote learning systems and the amount of students' independent workload increased exponentially. Self-regulated learning plays a crucial role in the learning process, and it is even more significant in remote learning as external regulation is low.

The aim of this research was to study students' self-evaluation on self-regulation processes during remote learning caused by the second wave of COVID-19 pandemic in autumn 2020. This paper presents results of a case study at a secondary school in Latvia. Over a period of two months regular surveys were carried out to investigate students' opinion on their metacognitive, motivational and behavioural processes during remote learning. Results were analysed to determine the overall situation, changes over time and differences between distinctive students' groups.

Results reveal that 10-12th grade students are more self-rigorous when evaluating their performance than 7-9th graders. It is also evident that girls have better self-regulation skills than boys but seem to neglect their own needs more than boys. These and other results point to the need for customized support to different student groups during remote learning in order to provide all students with an appropriate learning environment.
\end{abstract}

Keywords: COVID-19, remote learning, self-evaluation, self-regulated learning, self-regulation processes.

\section{Introduction}

Still recently, work of the state educational establishments (kindergartens, schools and colleges) in Latvia was based on the traditional face-toface learning. The situation changed dramatically in spring 2020 when COVID-19 spread all around the world and, due to the quarantine, schools were forced to go on remote teaching and learning and deliver all or part of the lessons online. In contrast to planned, well-ahead organized and designed online learning, schools had to face emergency remote teaching 
(Hodges et al., 2020) as it served as the only panacea during the crisis caused by COVID-19 (Dhawan, 2020), and schools had to provide the possibility to give instructions to students, conduct the classes online and secure the communication with the students and their families.

The remote teaching and learning process forced educators to be able to adapt to the situation highlighting their level of flexibility and ability to adjust their teaching style. Initially a lot of teachers hoped that this would only be a temporary inconvenience and were reluctant to shift their teaching style and methods. Nevertheless, this period demanded teachers to change and acquire the use of new information communication technologies and different platforms. In the survey carried out by the Ministry of Education and Science of Latvia and Edurio at the end of the school year in May 2020, 55\% of teachers mentioned the improvement of their IT skills as one of the main benefits, however, there still remained some teachers who had not conducted a single online class (End of semester surveys about remote learning, 2020).

When the second wave of COVID-19 hit Latvia in October 2020, schools already foresaw that remote learning would set in as an inevitable process. Due to this reason, notwithstanding the participation in the large scale survey organised by the Ministry of Education and Science of Latvia and Edurio (End of semester surveys about remote learning, 2020), which highlighted general tendencies, schools considered the necessity for ongoing surveys that are tailored to the needs of each school. To monitor the quality of the remote teaching and learning process, a lot of educational establishments worked out their own questionnaires identifying students and teachers' needs in order to support them in the remote learning process. Questionnaires for parents were also applied to collect their opinion about the learning process and the results of the surveys have already been presented (Daniela, Rubene, Rūdolfa, 2021; Martinsone, Stokenberga, 2021).

The aim of this research was to analyse the data collected by a survey at a secondary school in Latvia in November and December 2020. The questions related to students' ability of self-regulation were researched to determine students' opinion on their metacognitive, motivational and behavioural processes during remote learning caused by the second wave of COVID-19 pandemic in autumn 2020.

\section{Self-regulated learning}

Self-regulated learning competence plays a very important role, as its acquisition significantly contributes to the achievement of other goals in the learning process and further education (Kizilcec, Pérez-Sanagustín \& Maldonado, 2017). Currently, the new competence-based learning content and approach is introduced in the system of education in Latvia, which 
develops value-based knowledge, skills and attitudes, and self-regulated learning is included in the new developed curriculum as one of the six transversal skills and is an important purpose of education (Skola 2030, 2019).

In traditional face-to face learning environments, students who can effectively self-regulate their learning process are considered as more effective learners by educators and researchers (Boekaerts, 1999) and it has been proved that they tend to achieve better and have more positive developmental outcomes (Zimmerman \& Cleary, 2009). Self-regulated learning appears even more essential in the online learning environments as the learners' autonomy is high and the teachers' presence is low (Lehmann, Hahnlein, \& Ifenthaler, 2014) and not all learners are able to manage their learning process with minimal guidance (Wong, Baars, Davis, Zee, Houben \& Paas, 2019), but if students have well developed self-regulated learning skills they are more motivated to learn also when there are web based instructions used (Chang, 2005) which confirms the importance of self-regulated learning.

According to Barry Zimmerman (1986) self-regulated students are viewed as "metacognitively, motivationally, and behaviorally active participants in their own learning process" (p. 308). They are able to initiate and direct their learning and, instead of relying on teachers or parents, they know how to use self-learning strategies, have developed self-efficacy and are committed to academic goals (Zimmerman, 1989).

In accordance with Bandura's (1986) proposed triadic reciprocality, students learning not only is influenced by personal processes, but there is also a causational reciprocality among personal, environmental and behavioral processes. Based on this theory Zimmerman (1989) developed the first model of self-regulated learning.

Self-regulated learning includes cognitive, metacognitive, behavioural, motivational and emotional aspects of learning and a vast variety of variables and strategies that influence them, and it has been widely researched by educational psychology. Several self-regulated learning models were developed by Zimmerman; Boekaerts; Winne and Hadwin; Pintrich; Efklides; and Hadwin, and all of them were thoroughly researched and analyzed by Panadero (2017) stating that although the SRL models differ, all the authors agree that self-regulation consists of various processes (e. g., goal setting, monitoring, etc.) and that self-regulation is based on a cyclic approach, as the performance is analysed and the provided feedback suggests further improvements.

Bandura (1986) points out three essential subprocesses in self-regulation: self-observation, self-judgement, and self-reaction as performance-related subprocesses which are interrelated in a reciprocal way and Zimmerman 
(2000) develops a cyclic model with three phases of self-regulated learning: (1) forethought, (2) performance and (3) self-reaction, where forethought means pre-task activities, for example, goal setting and entering the task with self-efficacy for learning, performance or volitional control that occurs through self-control and self observation during the task completion, and self-reflection or posttask activities that involve self-evaluation, self-judgement and and self-reaction.

Zimmerman (1989) states that self-regulated learning can happen when a student can use personal processes in order to regulate behaviour and create an appropriate learning environment. Newman (2012) defines willingness to seek help as one the key motivational variables that directly affects self-regulation as it is intentional and goal-directed activity that students need to be able to apply to complete the task successfully in case of academic difficulties.

This research analysed the data collected by the school on students' self-evaluation on their, firstly, metacognitive processes (e. g., planning and organizing their learning process, self-monitoring and self-evaluating, etc.), secondly, motivational processes (e. g., self-efficacy, help-seeking skills, etc.) and, thirdly, behavioural processes (e. g., selecting, creating learning environment, etc.).

Taking into consideration the important role of self-regulation in the learning process and specific circumstances when all the learning is organized remotely the research question is put: how students evaluate their self-regulated learning skills during remote learning process, and how the self-evaluations differ among several student groups.

\section{Method}

This case study was carried out in a secondary school in Latvia where regular surveying was introduced for all students studying remotely during the period of data collection in November and December 2020 for students from grades 4-12. Surveys contained 1 open-ended question where students could suggest improvements for remote learning process at school, 2 closed-ended questions about their emotional well-being and learning success which students had to evaluate using Likert scale from 1-10 and 8 statements about learning which students had to consider, using Likert scale with 7 levels - from fully agreeing to fully disagreeing. There was a possibility to comment on each part of the survey and the statements were chosen, taking into consideration conclusions about the main challenges in remote learning from the statewide surveying organized by the Ministry of Education and Science of Latvia after the first remote learning period during the spring 2020 (End of semester surveys 
about remote learning, 2020). The chosen statements were linked with self-regulated learning processes:

1. Metacognitive processes (e. g., planning and organizing their learning process, self-monitoring and self-evaluating, etc.) - 4 statements.

1.1. It was clear what to do and when.

1.2. I completed the planned tasks.

1.3. I learned the planned content.

1.4. Learning was diverse.

2. Behavioural processes (e. g., selecting and creating a learning environment, etc.) - 3 statements.

2.1 Help from teachers was available.

2.2. There was an opportunity to collaborate with other students to learn.

2.3. I took care of my well-being - exercised, rested my eyes, ventilated the room, drank enough water, ate healthily and had a good night's sleep.

3. Motivational processes (e. g., self-efficacy, help-seeking skills, etc.) 1 statement.

3.1. It was exciting to learn.

Surveys were not anonymous as the collected data was used at an institutional level to determine and offer the necessary support for each student and alternative mechanisms, like individual conversations with class teachers and school support staff, were available. Students were informed about the purpose of data collection and had an option not to take the survey. Students' parents were informed about the school's work system during remote learning, including data collection through surveys and had an option to object and prevent their children from taking part in any surveying proposed by the schools during the remote learning. For the purposes of this research, both the school and the collected data was anonymized. Full information about particular students was given only to teachers and support personnel to provide needed support. School personnel, who were granted permission to access students' data, were informed about their responsibility to ensure data protection and compliance with ethical standards. Permission was granted by the school board to analyze the anonymized data in this research.

Surveying was organized after the lessons by class teachers 1-5 times a week according to the needs of each class. The class teachers met the students every morning before the lessons for 10-40 minutes during the class lesson and in the afternoons after studies, when the class teachers considered it to be necessary. Results of the surveys were used by class teachers during class lessons as well as in individual communications with 
students, offering additional support to students who experienced any difficulties, and help from a social pedagogue and school psychologist was also available.

Altogether 3044 unique responses were collected. For the purposes of this research it was decided to use responses gathered from grades 7-12, because these students spent the longest time learning remotely, therefore, 719 responses from students grades 4-6 were excluded from the analysis and summarising of the results discussed in this paper. 349 responses from the rest were automatically removed as duplicates. Authors of 7 responses could not have been identified, therefore, they were removed and 10 responses were handed in after the planned survey period and were not analysed. Remaining 1958 responses from 319 unique students were used in data analysis.

Surveys were created with Google Forms, data was collected and further handled in Google Spreadsheets and built-in automated features for data organizing, analysis and visualisation were used.

\section{Results and discussion}

To determine the overall situation concerning self-regulated learning aspects all collected answers were analysed (Fig. 1).

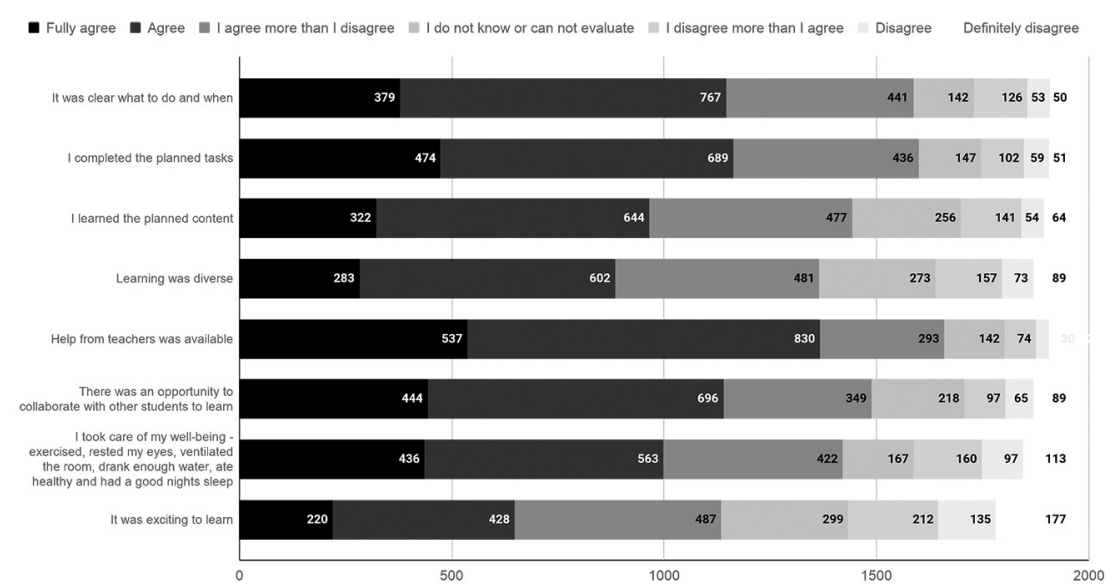

Figure 1. Students' self-evaluation of self-regulated learning aspects during remote learning

The highest self-evaluation is for the behavioural aspect of self-regulated learning and students consider that the necessary help from teachers is available. Followed by metacognitive aspects of self-regulated learning, 
students state that it was clear for them what and when they had to do and they managed to complete the planned tasks. The lowest self-evaluation is for the motivational aspect of self-regulated learning as many students do not feel that it is exciting to learn. Although students' overall average self-evaluation on their emotional well-being and learning success is high 7.3 and 7.4 from 10 respectively (where 1 is very bad and 10 is very good), it is seen that both indicators decreased over time (Fig. 2). This is consistent with other researches revealing that remote learning has additional negative effects over longer periods of time (Dhawan, 2020, Gottschalk, 2019, Iivari et al., 2020, Karalis, 2020, Reimer \& Schleiche, 2020, Rogers \& Shwetlena, 2020). However, it is crucial to keep in mind that we are examining widespread remote learning caused by pandemic, therefore, it is possible that the decrease in emotional well-being is caused not only by the remote learning process itself, but rather by a cluster of factors connected to pandemic (Hodges et al., 2020, Gottschalk, 2019), for example, students were not allowed to meet after school, and considering the important role of socialization in human development, this factor might have had a strong negative impact on students' well-being. A longitudinal study by Huckins and colleagues reveals that, compared to prior academic terms, students feel more sedentary, anxious and depressed. In addition, a wide variety of behaviours, including increased phone usage, decreased physical activity and fewer locations visited, are associated with fluctuations in COVID-19 news reporting (Huckins et al., 2020).
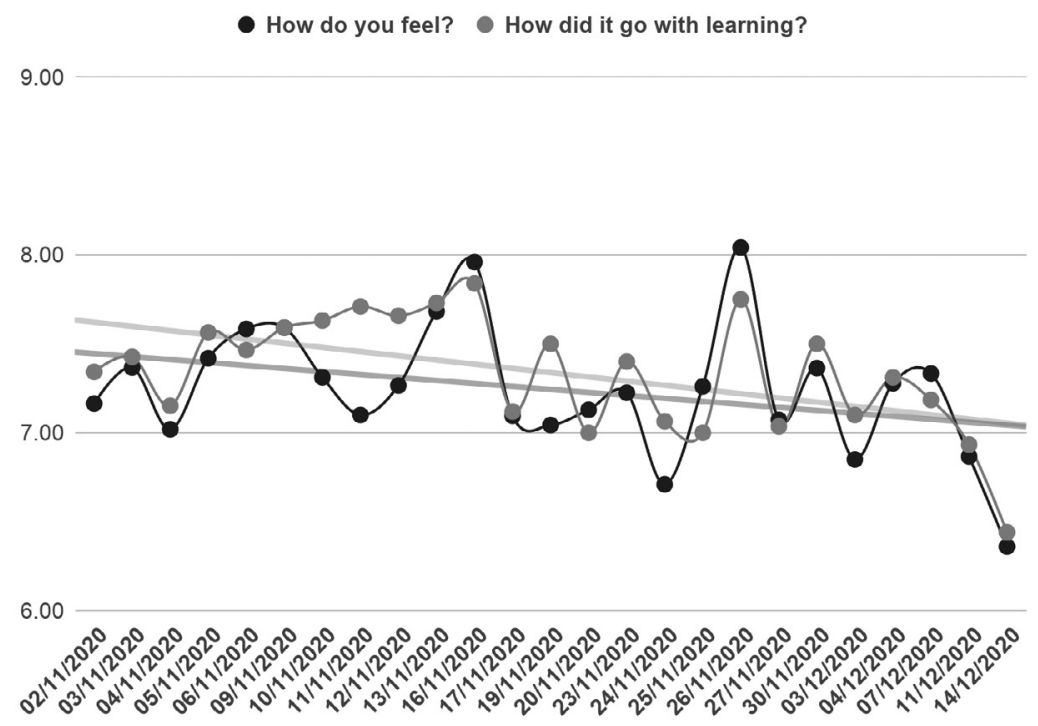

Figure 2. Students' average self-evaluation over time during remote learning 
It is also important to take into consideration that the data was collected during November and December. December in Latvia is the end of the first school semester, therefore, additional stress might have been caused by the final testing and marking, which could have had a negative impact on students' emotions and, consequently, self-evaluation.

Student groups with highest and lowest overall self-evaluation were also compared (Fig. 3). Students with lower overall self-evaluation had least problems with behavioural aspects of self-regulated learning. Most problems for this student group occurred with the motivational and metacognitive aspects of self-regulated learning as many of them did not find learning exciting, did not feel that learning was diverse or they had learned the planned content. This could be explained by students having less understanding of the learning process and learning strategies and, therefore, being less able to organize their own learning process in a way that is productive for them (Lee \& Choi, 2017). Not being able to direct themselves successfully, further decreased their willingness to learn, hence creating a downward spiral as they were not motivated to learn, consequently, they were not able to do it successfully, which in turn decreased their motivation even more (Deci \& Ryan, 1985, 2002a, 2002b; Wigfield et al., 2007).

Fluctuation of self-evaluation of self-regulated learning for students with highest overall self-evaluation results was lower. This student group had the highest evaluation for availability of help from teachers, which could indicate both better relationships with teachers and being able to use the offered help. Taking care of their well-being is one of the lowest evaluated aspects of self-regulated learning for this student group. It is possible that this aspect of self-regulated learning has been activated less than others before the pandemic, as in the traditional learning environment teachers planned and organised students' learning process, physical activities and lunches, taking into consideration proper lighting and ventilation of the classrooms. Therefore, this is an entirely new set of tasks that students have to master in order to learn successfully. Other researches have shown that balancing learning and private life is one of the main challenges students face in e-learning (Parkes et al., 2014; Wang et al., 2020).

Although the evaluation is high with $81 \%$ of students agreeing or definitely agreeing that it was exciting for them to learn, the motivational aspect is the lowest evaluated of self-regulated learning aspects for the student group with the highest overall self-evaluation as well. Considering that learning motivation is based on both intrinsic and extrinsic factors (Wigfield et al., 2007), additional support from teachers might be needed for students to fully engage in learning. 


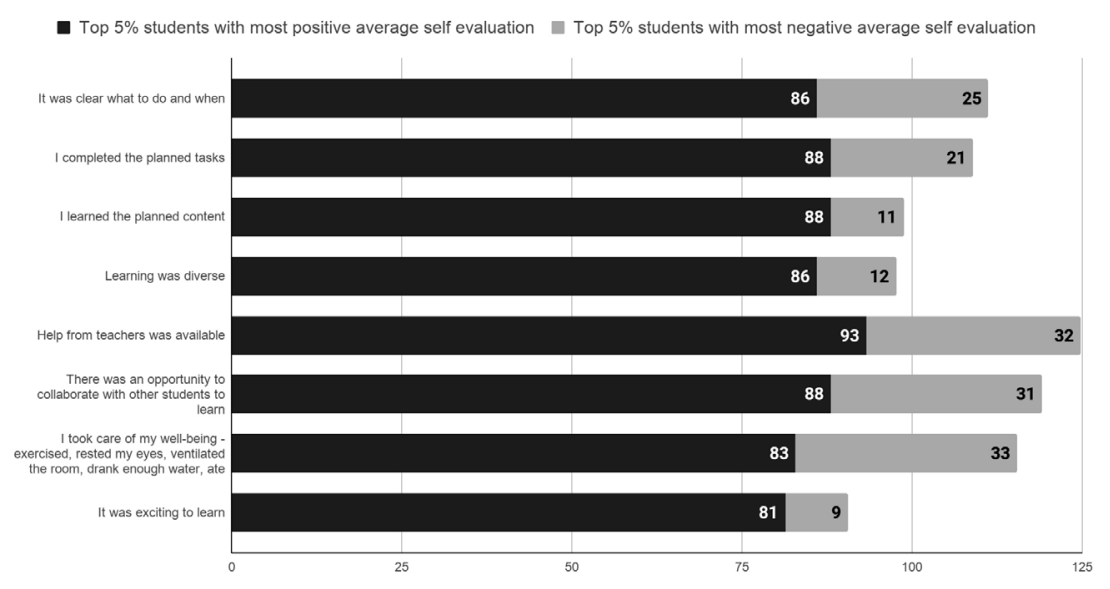

Figure 3. Percentage of students with overall highest and lowest self-evaluation with positive self- evaluation in each self-regulated learning aspect

Fig. 4 depicts that $7-9^{\text {th }}$ grade students have a better self-evaluation in all self-regulated learning aspects, except for collaboration with other students, where $10-12^{\text {th }}$ grades evaluate themselves higher and for the availability of help from teachers, where evaluation is the same. It is possible that for older students the learning content becomes more complex, which could cause issues with understanding and completion of the assigned tasks while working remotely, thus creating the difference in self-evaluations. 10-12th grade students also have lower self-evaluation for the motivational aspect of self-regulated learning as only $31 \%$ of them agree or strongly agree that learning is exciting for them, compared to $37 \%$ in the younger students' group. This is strongly linked to higher dropout risks for older students and is consistent with other research (Reimer \& Schleiche, 2020; Rogers \& Shwetlena, 2020). It might also be possible that older students evaluate themselves more rigorously than younger students because they have developed overall more complex self-evaluation and critical thinking skills.

As seen in Fig. 5, girls evaluate themselves higher in all self-regulated learning aspects, except for taking care of themselves, where boys evaluate themselves higher, and for learning being exciting both groups have equal evaluation. It has been shown in other research that girls have better self-regulation skills than boys (Duckworth \& Seligman, 2006; Lummis \& Stevenson, 1990; OECD, 2015). Data from this research show that girls collaborate more with teachers and amongst classmates and are more successful with completing the planned tasks. However, this diligence could come at a cost of their well-being, since girls evaluate themselves considerably 
lower at taking care of themselves - only $48 \%$ positive evaluations, whereas boys have $55 \%$ positive evaluations respectively. Previous research shows that girls' efforts to work up to their fullest might also cause a lot of stress and disappointment when the highest results are not achieved (Pomerantz, Altermatt \& Saxon, 2002).

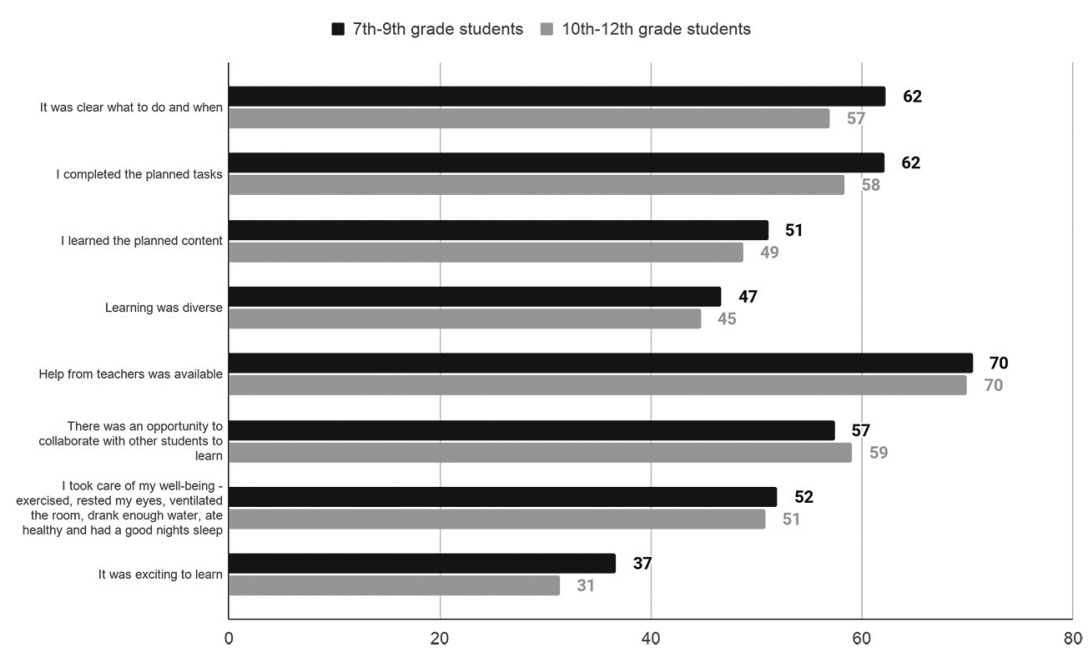

Figure 4. Percentage of students from grades 7-9 and grades 10-12 with positive self evaluation in each self-regulated learning aspect

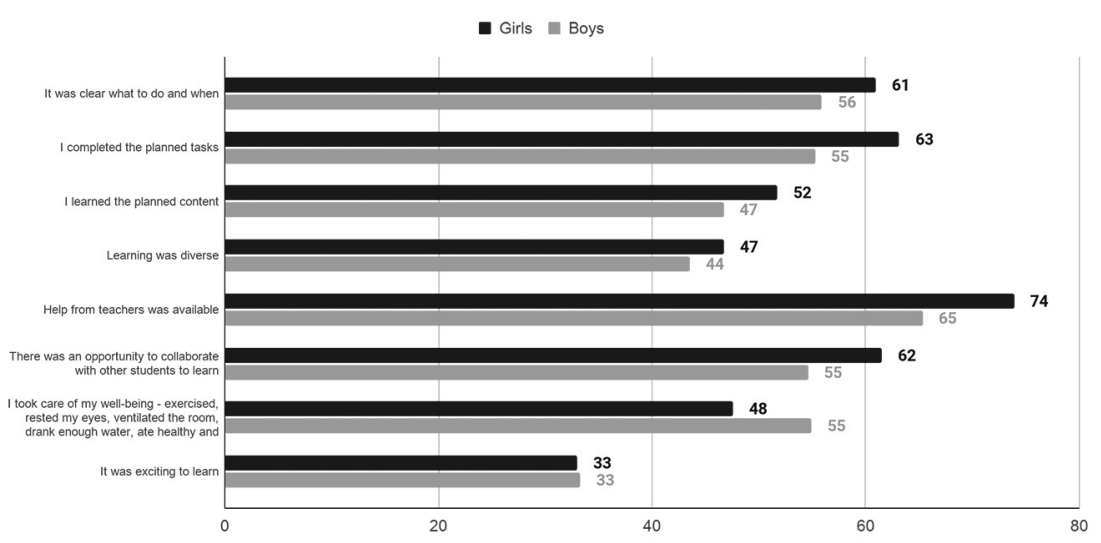

Figure 5. Percentage of boys and girls with positive self evaluation in each selfregulated learning aspect 


\section{Conclusions}

The aim of this research was to study students' self-evaluation on self-regulation processes during remote learning caused by the second wave of COVID-19 pandemic in autumn 2020 and analyse how their self-evaluations differ among distinctive students' groups.

It can be concluded that students with lower self-evaluation need additional support to improve the metacognitive aspect of self-regulated learning. Mastering new learning strategies might help improve results.

$10-12^{\text {th }}$ grade students might be more self-rigorous in evaluating their performance, and thus it is important to ensure they do not get discouraged by it. Helping students set ambitious but realistic collective and individual learning goals might help.

Similar to the previous research (OECD, 2015), this research shows that girls have better self-regulation skills and are more diligent learners. As a result, girls could neglect their own needs more than boys, which could lead to negative consequences, especially in the long term. Implementing self-care topics in learning content, ensuring that students take care of their learning environment and practice healthy habits, could be beneficial for all students.

The research shows that additional support is needed to ensure students' well-being, and consequently, ability to learn during remote learning. Class teachers, as well as school support staff, might help students who feel overwhelmed.

It is crucial to help students find ways to motivate themselves to learn during remote learning. Lack of social activities is one of the main concerns and, therefore, implementing more collaborative learning activities like discussions, group work and peer-review might help.

More research is needed to clarify the differences between self-regulated learning skills in distinctive student groups (age, gender, higher and lower achieving students), this could help provide students with more individualised support. It would also be beneficial to further research the impact of self-regulated learning processes on students' academic achievement during remote learning, this could help provide students with an appropriate learning environment. 


\section{References}

Bandura, A. (1986). Social foundations of thought and action: A social cognitive theory. Englewood Cliffs, NJ: Prentice Hall.

Boekaerts, M. (1999). Self-regulated learning: Where we are today. International Journal of Educational Research, 31(6), 445-457.

Chang, M. M. (2005). Applying self-regulated learning strategies in a web-based instruction - An investigation of motivation perception. Computer Assisted Language Learning, 18(3), 217-230.

Daniela, L., Rubene, Z., \& Rūdolfa, A. (2021). Parents' perspectives on remote learning in the pandemic context, Sustainability, 13(7), 3640.

Deci, E. L., \& Ryan, R. M. (1985). Intrinsic motivation and self-determination in human behavior. New York: Plenum Press.

Deci, E. L., \& Ryan, R. M. (2002a). The paradox of achievement: The harder you push, the worse it gets. In J. Aronson (Ed.), Improving academic achievement: Impact of psychological factors on education (pp. 61-87). San Diego, CA: Academic Press.

Deci, E. L., \& Ryan, R. M. (2002b). Self-determination research: Reflections and future directions. In E. L. Deci \& R. M. Ryan (Eds.), Handbook of self-determination theory research (pp. 431-441). Rochester, NY: University of Rochester Press.

Dhawan, S. (2020). Online learning: A panacea in the time of COVID-19 crisis. Journal of Educational Technology Systems. https://doi.org/ 10.1177/0047239520934018

Duckworth, A. L., \& Seligman, M. E. P. (2006). Self-discipline gives girls the edge: Gender in self-discipline, grades, and achievement test scores. Journal of Educational Psychology, 98(1), 198-208.

End of semester surveys about remote learning (2020), Ministry of Education and Science of Latvia, Edurio. Retrieved from: https://home.edurio.com/izm-gada-nosleguma-aptaujas

Gottschalk, F. (2019). Impacts of technology use on children: Exploring literature on the brain, cognition and well-being, OECD Education Working Papers, No. 195, OECD Publishing, Paris. https://doi.org/10.1787/8296464e-en

Hodges, C., Moore, S., Lockee, B., Trust, T., \& Bond, A. (2020). The difference between emergency remote teaching and online learning. Retrieved from: https://er.educause. edu/articles $/ 2020 / 3 /$ the-difference-between-emergency-remote-teaching-and-onlinelearning $\% \mathrm{C} 2 \% \mathrm{~A} 0 \% \mathrm{C} 2 \% \mathrm{~A} 0$.

Huckins, J. F., DaSilva, A. W., Wang, W., Hedlund, E., Rogers, C., Nepal, S. K., et al. (2020). Mental health and behavior of college students during the early phases of the COVID-19 pandemic: Longitudinal smartphone and ecological momentary assessment study. Journal of Medical Internet Research, 22(6), e20185.

Iivari, N., Sharma, S., \& Ventä-Olkkonen, L. (2020). Digital transformation of everyday life - How COVID-19 pandemic transformed the basic education of the young generation and why information management research should care? International Journal of Information Management, Volume 55.

Karalis, T. (2020). Planning and evaluation during educational disruption: lessons learned from COVID-19 pandemic for treatment of emergencies in education. European Journal of Education Studies, Volume 7, Issue 4. 
Kizilcec, R. F., Pérez-Sanagustín, M., \& Maldonado, J. J. (2017). Self-regulated learning strategies predict learner behavior and goal attainment in Massive Open Online Courses. Computers \& Education, 104, 18-33.

Lee, J. \& Choi, H. (2017). What affects learner's higher-order thinking in technologyenhanced learning environments? The effects of learner factors. Computers \& Education, $115,143-152$.

Lehmann, T., Hähnlein, I., \& Ifenthaler, D. (2014). Cognitive, metacognitive and motivational perspectives on reflection in self-regulated online learning. Computers in Human Behavior, 32, 313-323.

Lummis, M., \& Stevenson, H. W. (1990). Gender differences in beliefs and achievement: A cross-cultural study. Developmental Psychology, 26(2), 254-263.

Martinsone, B., \& Stokenberga, I. (2021). Parents' perspective on distant learning at home during COVID-19 related restrictions. In Distance Learning in Times of Pandemic: Issues, Implications and Best Practice; Taylor \& Francis, Oxfordshire, UK, 2021; in press, ISBN 9780367765705.

Newman, R. S. (2012). The motivational role of adaptive help seeking in self-regulated learning. In Schunk, D. H., \& Zimmerman, B. J. (Eds.), Motivation and Self-Regulated Learning: Theory, Research, and Applications (pp. 315-337). Routledge.

OECD (2015). The ABC of Gender Equality in Education: Aptitude, Behaviour, Confidence. PISA, OECD Publishing, Paris.

Panadero, E. (2017). A Review of self-regulated learning: Six models and four directions for research. Frontiers in Psychology, 8, 422.

Parkes, M., Stein, S., \& Reading, C. (2014). Student preparedness for university e-learning environments. The Internet and Higher Education, 25, 1-10.

Pomerantz, E., Altermatt, E. R., \& Saxon, J. L. (2002). Making the grade but feeling distressed: Gender differences in academic performance and internal distress. Journal of Educational Psychology, 94, 396-404.

Reimer, F. M., \& Schleiche, A. (2020). A framework to guide an education response to the COVID-19 Pandemic of 2020. OECD. Retrieved from: https://www.hm.ee/sites/ default/files/framework_guide_v1_002_harward.pdf

Rogers, H., \& Shwetlena, S. (2020). The COVID-19 Pandemic: Shocks to Education and Policy Responses. World Bank: Washington, DC, USA, 2020.

Skola 2030 (2019). Caurviju prasmes (Transversal skills). Retrieved from: https://www. skola2030.lv/lv/macibu-saturs/merki-skolenam/caurviju-prasmes

Wang, C., Pan, R., Wan, X., Tan, Y., Xu, L., \& Ho, C. S., et al. (2020). Immediate psychological responses and associated factors during the initial stage of the 2019 coronavirus disease (COVID-19) epidemic among the general population in China. International Journal of Environmental Research and Public Health, 17(5), 1729.

Wigfield, A., Eccles, J. S., Schiefele, U., Roeser, R. W., \& Davis-Kean, P. (2007). Development of achievement motivation. In the Handbook of Child Psychology and Developmental Science (pp. 1-44).

Wong, J., Baars, M., Davis, D., Zee, T. V. Z., Houben, G. \& Paas, F. (2019). Supporting self-regulated learning in online learning environments and MOOCs: A systematic review. International Journal of Human-Computer Interaction, 35:4-5, 356-373.

Zimmerman, B. J. (1986). Becoming a self-regulated learner: Which are the key subprocesses? Contemporary Educational Psychology, 11(4). 
Zimmerman, B. J. (1989). A social cognitive view of self-regulated academic learning. Journal of Educational Psychology. 81 (3): 329-339.

Zimmerman, B. J. (2000). Attaining self-regulation: A social cognitive perspective. In M. Boekaerts, P. R. Pintrich, \& M. Zeidner (Eds.), Handbook of self-regulation (pp. 13-39). San Diego, CA: Academic Press.

Zimmerman, B. J., \& Cleary, T. J. (2009). Motives to Self-Regulate Learning. In K. R. Wentzel, \& A. Wigfield (Eds.), Handbook of Motivation at School (pp. 247-264). New York: Routledge. 